\title{
A.JO「互
}

Africa Journal of Teacher Education

ISSN 1916-7822. A Journal of Spread Corporation

Vol. 6 No. $1 \quad 2017 \quad$ Pages 56-64

\section{THE USE OF CRONBACH ALPHA RELIABILITY ESTIMATE IN RESEARCH AMONG STUDENTS IN PUBLIC UNIVERSITIES IN GHANA.}

\author{
Frank Quansah \\ Department of Education and Psychology \\ University of Cape Coast, Ghana. \\ frank.quansah1@stu.ucc.edu.gh
}

\begin{abstract}
This study examines the use of Cronbach alpha reliability estimate in research among university students in Ghana. An exploratory research design was employed in the study. University students' (both undergraduate and post-graduate) research works were selected from three public universities in Ghana. With the use of an inclusion criteria, purposive sampling technique was used to sample 100 research works conducted by students. The sampled research works were examined to evaluate how the students used Cronbach alpha reliability estimate. It was revealed that $91 \%$ of the works properly satisfied the conditions for the use of Cronbach alpha. However, $81 \%$ of the students calculated for the alpha for multiple constructs which suggests that alpha was treated as a measure of multidimensionality instead of internal consistency. It is recommended that applied courses in research and statistics should be mounted in the various public universities in Ghana. Workshops and seminars should also be organised for both students and lecturers on the use of Cronbach alpha reliability estimate.
\end{abstract}

Keywords: Reliability, internal consistency, Likert scale, unidimensionality, multidimensionality.

\section{INTRODUCTION}

Data, most often, collected in the social sciences, medicine, marketing as well as business, which are related to opinions, personalities, attitudes, emotions, and descriptions of events or people's environment involve the utilisation of items on a Likert scale (Glien \& Glien, 2003). Thus, as researchers attempt to quantify constructs which cannot be directly measured, summated ratings and multiple-item scales are usually employed to quantify the construct(s) of interest. The Likert 
scale was invented by Rensis Likert (1931), who labelled this method for the measure of attitudes. In agreement to Likert's view, McIver and Carmines (1981, p. 22-23) describes the Likert scale as:

A set of items, consisting of approximately an equal number of favorable and unfavorable statements relating to the attitude object, is given to a group of subjects. They are requested to respond to each statement in terms of their own degree of agreement or disagreement. Particularly, they are required to select one of five responses: strongly agree, agree, undecided, disagree, or strongly disagree. The specific responses to the items are combined so that individuals with the most favorable attitudes will have the highest scores while individuals with the least favorable (or unfavorable) attitudes will have the lowest scores. While not all summated scales are created according to Likert's specific procedures, all such scales share the basic logic associated with Likert scaling.

The reliability of items on a Likert scale is something that cannot be overlooked since every researcher deems it necessary to collect accurate and objective data in conducting research. There is, therefore, the need to estimate the reliability of the scale which is being used to measure the construct of interest. The reliability estimate for items on a Likert scale is measured using the reliability method known as Cronbach Alpha. Lee Cronbach in 1951 developed the Cronbach Alpha to offer a measure of the internal consistency of a scale or test, expressed as a number between 0 and 1(Cronbach, 1951) which is used for items whose responses are on a scale. Internal consistency, according to Tavakol and Dennick (2011), is associated with the interrelatedness of a sample of items on a test. It is important to note that internal consistency is a necessary condition but not sufficient enough for the measure of homogeneity or unidimensionality in a sample of test items (Cortina, 1933; Green, Lissitz, \& Mulaik, 1977).

Schmitt (1996) reported that presenting coefficient alpha as an index of reliability or the internal consistency of psychological construct has turned out to be routine practice in almost all social science and psychological research which makes use of the measurement of multiple-item of a construct. From Miller's (1995) view, the concept of reliability, basically, assumes that there is the existence of unidimensionality in a sample of test items and thus, a major underestimation of reliability is caused if this assumption is violated. Studies have documented that a multidimensional test, essentially, does not have a lower alpha coefficient than a unidimensional test. Therefore, a more detailed view of alpha is that it cannot basically, be construed as an index for the internal consistency of a test (Cortina, 1933; Green, Lissitz, \& Mulaik, 1977; Green \& Thompson, 2005). 
In actual fact, Cronbach (1951), categorically indicated that alpha is an underestimate of reliability unless the inter-item correlation matrix is of unit rank (i.e., unidimensional).

On another dimension, if a test consists of more than one construct, it may not make sense to present alpha for the whole test as the larger volume of items or questions will inevitably bloat the value of alpha. Thus, alpha should, in principle, be estimated for each of the construct rather than for the whole scale (Nunnally \& Bernstein, 1994; Cohen \& Swerdlik, 1996). This is because alpha is not a measure of unidimensionality (Cortina, 1933; Green, Lissitz, \& Mulaik, 1977) or multidimensionality (Schmitt, 1996). Again, alpha is affected by the number of items on an instrument. Thus, few number of items (less than 10) would definitely yield a small alpha value and vice versa (Nunnally \& Bernstein, 1994; Streiner, 2003). More essentially, alpha is entrenched in the 'tau equivalent model' which operates on the assumption that each item on an instrument is a measure of the same latent trait on the same scale. Hence, if multiple construct/factor underlie the items on a scale, this assumption is violated. This result is an underestimation of alpha as well as the reliability of the instrument (Green \& Thompson, 2005). If the number of test items, on the other hand, is too small, the assumption of tau-equivalence will also be violated and this will result in an underestimation of reliability (Graham, 2006).

A number of studies have discussed the misconceptions, misuses and abuses of Cronbach alpha method for the estimation of reliability (Schmitt, 1996; Tavakol and Dennick, 2011; Bademci, 2014; Brown, 2002). While some scholars have examined the lapses in the use of alpha, others have compared the effectiveness of alpha to other methods of estimating reliability. All these literature together provide a comprehensive understanding of the use of Cronbach alpha. However, no study has been conducted to examine how researchers (e.g. lecturers, students, employers, etc) use Cronbach alpha reliability. This study, therefore, seeks to examine the use of alpha in research among university students in Ghana. This study was conducted among university students because these students carry out research work which is supposed to give insight on pertinent issues to stakeholders across the various sectors of the economy. This means that the findings from the students' research works conducted in tertiary institutions are quintessential to policy and practice in various specialisations. It is important for students to collect data free of errors in order to come up with reliable findings. Thus, their knowledge on the use of this method of estimating reliability, obviously, would determine the dependability of the students' research findings. 


\section{METHODOLOGY}

The research design employed was exploratory design. The study covered three public universities in Ghana: University of Cape Coast (UCC), Kwame Nkrumah University of Science and Technology (KNUST) and University of Ghana (UG). The study made use of secondary data project and thesis work of students. These were selected based on the following criteria:

1. Research work which were conducted not more than the previous 5 years (i.e from 2010 to 2015).

2. Studies which utilised questionnaire as the data collection instrument.

3. Works which used Cronbach alpha reliability method for estimating the reliability of the instrument.

Through purposive sampling, 100 research works of students (50 undergraduate project works and 50 post-graduate thesis/dissertation) were sampled from the three (3) universities. Table 1 gives breakdown on the proportion of research works sampled.

\begin{tabular}{llll}
\hline Level & UG & KNUST & UCC \\
\hline Undergraduate & $10(10)^{*}$ & $14(14)$ & $26(26)$ \\
Post-graduate & $12(12)$ & $19(19)$ & $19(19)$ \\
\hline Total & $\mathbf{2 2}(22)$ & $\mathbf{3 3}(\mathbf{3 3})$ & $\mathbf{4 5}(\mathbf{4 5})$
\end{tabular}

\section{Table 1: The Proportion of Research Work Sampled from each University}

*Percentages in parenthesis

Each work was thoroughly examined to find out whether the responses of the construct of interest was on Likert scale and whether the reliability estimate was calculated on single or multiple construct. The examination of the research work was done by six (6) post-graduate students of Educational Measurement and Evaluation (MPhil) of the University of Cape Coast. These students were given an orientation on the objective of the study as well as the mode of data collection. The examination of the sampled research works lasted for a month. All the collected data were collated for analysis. Simple frequency count and percentages were used for the analysis.

\section{RESULTS}

The analysis was done to determine, in general, whether university students in Ghana used Cronbach alpha reliability estimate correctly in their research work. Specifically, the study explored 
whether the constructs of interest were measured on a scale or not and whether reliability estimate were calculated for single or multiple construct(s). Figure 2 and Table 2 present the details.

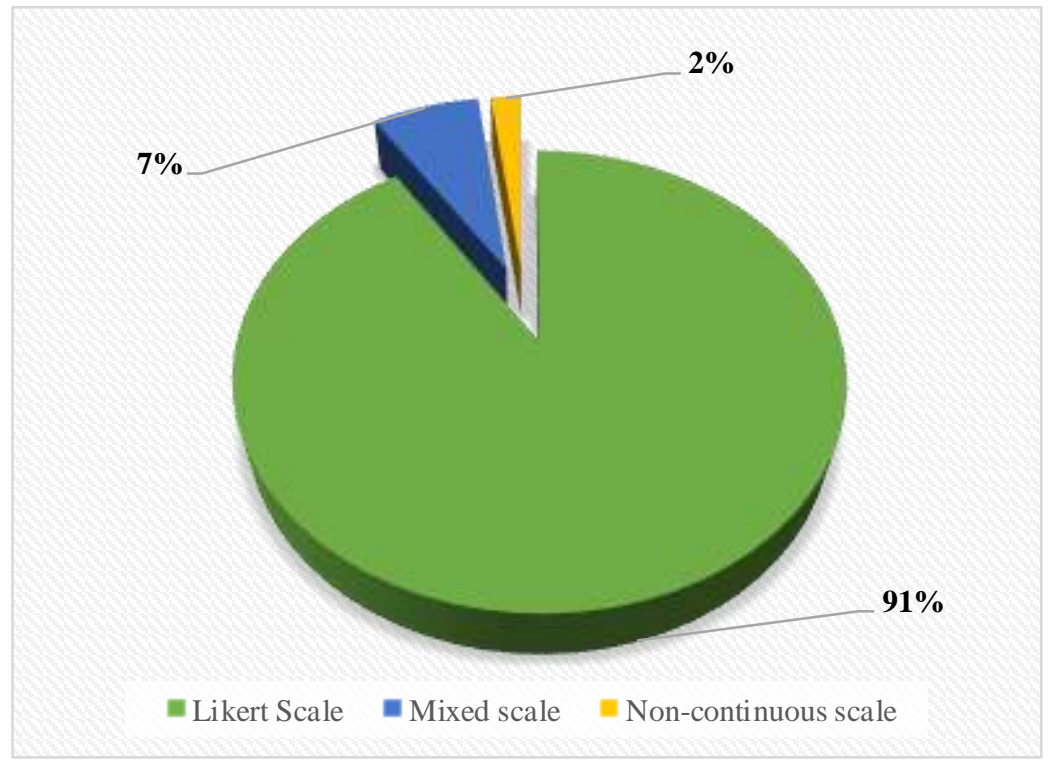

Figure 1: Proportion of works which used Likert scale, mixed scale and non-continuous scale items

It was revealed that $91 \%$ of research works examined used questionnaires with items or constructs being measured using Likert scale (Figure 1). About 7\% of the students' research work used a questionnaire which used a mixed scale in measuring construct(s). The mixed scale, in this context, refers to the situation where a construct is quantified using different scales. For instance, some of the studies conducted sought to find out the attitude of teachers in teaching laboratory work. While some of the items used in the measurement of attitude were measured on a five point Likert scale, other items were also on dichotomous scale (Yes or No), even though all these questions were measuring the same construct (i.e. attitude). Even though $2 \%$ of the examined research works used Cronbach alpha to estimate reliability, the construct of interest was not measured on a continuous scale.

Table 2, on the other hand, provides information on whether alpha estimate was calculated for single construct or multiple constructs. It was discovered that only $9 \%$ of the students estimated the reliability (alpha) for each single construct. Moreover, $81 \%$ of the students combined multiple construct and estimated the reliability for the whole instrument. Interestingly, $10 \%$ of the students calculated for the reliability estimate for each single construct and at the same time calculated for the alpha estimate for all the construct combined. 
Table 2: Students use of Alpha for estimating construct(s)

\begin{tabular}{lll}
\hline Estimate for construct(s) & Frequency & Percentage \\
\hline Single construct & 9 & 9.0 \\
Multiple construct combined & 81 & 81.0 \\
Both single and combined multiple constructs & 10 & 10.0 \\
\hline Total & $\mathbf{1 0 0}$ & $\mathbf{1 0 0 . 0}$ \\
\hline
\end{tabular}

Source: Authors' Fieldwork (2017)

\section{DISCUSSION}

The current study sampled 100 thesis and project work of university students who employed Cronbach alpha in estimating the reliability of research instrument used. The study revealed that the majority of students made the right decision as to when Cronbach alpha is used per the scale the construct is being measured on. Cronbach alpha reliability estimate is appropriately used when the items measuring a particular construct is measured on continuous scale (Likert scale). With regards to the current study, $91 \%$ of the students rightly used the Cronbach alpha for items which were measured on a Likert scale. However, some of the students used the Cronbach alpha to estimate the reliability of items which are measured on dichotomous responses and non-continuous scale. This was evident as $9 \%$ of research works examined, treated the Cronbach alpha as if it is used for estimating the reliability of items measured on dichotomous responses. This suggests that some university students do not know the condition to satisfy in the use of Cronbach alpha for estimating the reliability of a construct even though most of them were aware of such condition.

Surprisingly, the study also revealed that only $9 \%$ used Cronbach alpha to estimate the reliability of each single construct of interest. This was a step in the right direction as it may not make sense to present alpha for the whole test as the larger volume of items or questions will inevitable bloat the value of alpha (Nunnally \& Bernstein, 1994). Cohen and Swerdlik (1996) added that alpha should be estimated for each of the construct rather than for the whole scale. About $91 \%$ of the students, however, treated Cronbach alpha as a measure of multidimensionality. This indicates that university students have little knowledge with regards to what exactly Cronbach alpha does. It is important to note that alpha is not even a measure of unidimensionality let alone a measure of multidimensionality (Cortina, 1933; Green, Lissitz, \& Mulaik, 1977). According to Green and Thompson (2006), if multiple construct/factor underlie the items on a scale, it will result 
in an underestimation of alpha as well as the reliability of the instrument. It is therefore essential to use Cronbach alpha for estimating the reliability of a single construct at a time.

\section{CONCLUSION AND RECOMMENDATIONS}

The findings from my research show that students are aware of the condition to satisfy before Cronbach alpha estimate should be used. However, most of the students treated alpha as a measure of multidimensionality, a clear demonstration that alpha was not being properly used. This has implications for the kind of conclusions that would be drawn from the data collected using these instruments. The most significant one is equally obvious: once a number of constructs are combined, the items also increase, thereby inflating the value of alpha. Thus, the value of alpha will not reflect the actual reliability of the scales being used. This inappropriate use of Cronbach alpha estimate by these students is likely to stem from how statistics course is taught at the university level. It appears like the general statistics course taken across Ghana's public universities largely focuses on theoretical understanding. Thus, students are not given the chance to practically apply these statistics concepts. This might also be as a result of the fact that statistics, as a course, is taught independently from research method course. Hence, students lack the experience of correctly applying their knowledge in statistics in the research context.

In many cases, these university students think all items on a questionnaire measure a specific construct of interest at a time, forgetting that a questionnaire can be made up of a number of different scales for measuring different constructs. The consequence of this belief is the likelihood that students would treat alpha as a measure of multidimensionality. That a majority of the sampled research works examined in this study have a sub-topic captioned "reliability of the instrument" demonstrates this. This seems to have misled the students to think that reliability estimate is for the whole questionnaire rather than for only the constructs on the questionnaire. Such cases increase the likelihood that students would treat a number of scales measuring different constructs as one.

The inability of these Ghanaian university students to properly use Cronbach alpha reliability estimate in the research context seems to be due largely to how Cronbach alpha is being taught as their works demonstrate a lack of in-depth knowledge of its use. However, my examination of students' research works does not provide the exact and precise indication of the knowledge students have on the use Cronbach alpha. It is essential that further studies be conducted to examine quality of the knowledge of university students in the use of Cronbach alpha reliability estimate. It is recommended that more applied courses in research and statistics be mounted across public universities in Ghana and that workshops and seminars be organised for students on the use 
of Cronbach alpha reliability estimate. Lecturers, irrespective of their area of specialisation, should also be trained in research and statistics through conferences, workshops and seminars. This is because the research works examined in this study were approved and signed off by supervisors, who are lecturers. It is obvious that some of the lecturers would benefit from having a more comprehensive understanding of the use of Cronbach alpha reliability estimate.

\section{REFERENCE}

Bademci, V. (2014). Cronbach alpha is not a measure of unidimensionality or homogeneity. Journal of Computer and Education Research, 2(3), 19-27.

Brown, J. D. (2002). The Cronbach alpha reliability estimate. JALT Testing \& Evaluation SIG Newsletter, 6(1), 17-18.

Cohen, R., \& Swerdlik, M. (2010). Psychological testing and assessment. Boston: McGraw-Hill Higher Education.

Cortina, J. (1993). What is coefficient alpha: an examination of theory and applications? Journal of Applied Psychology, 78, 98-104.

Cronbach, L. (1951). Coefficient alpha and the internal structure of tests. Psychomerika, 16, 297334.

Glien, J. A., \& Glien, R. R. (2003). Calculating, interpreting, and reporting Cronbach's alpha reliability coefficient for Likert-Type scales. Presented at the Midwest Research-toPractice Conference in Adult, Continuing, and Community Education, The Ohio State University, Columbus, OH, October 8-10, 2003.

Graham, J. (2006). Congeneric and (Essentially) Tau-Equivalent estimates of score reliability: what they are and how to use them. Educational Psychological Measurement, 66, 930-944.

Green, S, \& Thompson, M. (2005). Structural equation modeling in clinical psychology research In: Roberts, M., \& Ilardi, S. (Eds). Handbook of research in clinical psychology. Oxford: Wiley-Blackwell.

Green, S., Lissitz, R., \& Mulaik, S. (1977). Limitations of coefficient alpha as an index of test unidimensionlity. Educational Psychological Measurement, 37, 827-38. 
Likert, R. (1931). A technique for the measurement of attitudes: Archives of Psychology. New York: Columbia University Press.

McIver, J. P., \& Carmines, E. G. (1981). Unidimensional scaling. Thousand Oaks, CA: Sage.

Miller, M. (1995). Coefficient alpha: a basic introduction from the perspectives of classical test theory and structural equation modeling. Structural Equation Modeling, 2, 255-73.

Nunnally, J. C., \& Bernstein, I. H. (1994). Psychometric theory (3 ${ }^{\text {rd }}$ ed.). New York: McGrawHill.

Schmitt, N. (1996). Uses and abuses of coefficient alpha. Psychological Assessment, 8, 350-353.

Streiner, D. (2003). Starting at the beginning: an introduction to coefficient alpha and internal consistency. Journal of Personality Assessment, 80, 99-103.

Tavakol, M., \& Dennick, R. (2011). Making sense of Cronbach alpha. International Journal of Medical Education, 2, 53-55 